\title{
Mar enterrado, mar compartido, mar separado. Distintas formas de ser marinero en las Baleares
}

\author{
AlEJANDRO MiQuel NOVAJRA \\ Universitat de les Illes Ballears
}

\section{INTRODUCCIÓN}

La presencia de grandes espacios costeros, con una distribución entre escarpes, bahías y playas relativamente favorable a estos dos últimos accidentes, junto a un mar cerrado, comparativamente tranquilo y plurisecularmente surcado por miles de naves de múltiples culturas, imperios, civilizaciones, formaciones sociales diferentes, constituye la base ideal para el asentamiento de comunidades marineras. Su crecimiento y el incremento de su influencia valorativa y categorial en el ámbito del entorno debería ser casi exponencial. Si, además, unimos a todo lo anterior el hecho isleño y, más aún, en una situación geográfica históricamente central en el seno del Mediterráneo Occidental, no sería difícil aventurar que las Islas Baleares son esencialmente un universo marítimo.

Sin embargo la realidad cultural y social actual dista mucho de poder ser definida de esa manera. Ciertamente, tal y como afirma, entre otras posiciones, el materialismo cultural, la geografía y la ecología determinan en gran medida las formaciones culturales; pero no es menos constatable que los procesos históricos, las contradicciones inherentes a las formas en que tales culturas se asientan, varían y permanecen, intervienen con intensidad superior en las respuestas y las construcciones de las formaciones sociales. Mallorca, Menorca, Eivissa y Formentera son un claro ejemplo de la extraña paradoja resultante: el mar marginado.

De ahí que el presente trabajo, que muchos esperarían húmedo, goteante, resquebrajado por el alto contenido salino de las aguas mediterráneas, deba arrastrase necesariamente serpenteando entre almendros, olivos, algarrobos, campos de cereal y, fundamentalmente, masas de cemento turístico para arribar a la mar. De la vieja Llotja de Ciutat de Mallorca apenas si queda una desgastada y mal restaurada bóveda, aparentemente de marés $^{1}$, que alberga exposiciones periódicas que en poco o en

1 Piedra margosa abundante en las construcciones isleñas. 
nada se relacionan con la fluida y rica navegación que la hizo institución fundamental en el Mare Nostrum. Las escasas y, a menudo, nuevas gentes que viven y trabajan en la mar, o constituyen un universo aparte $o$ permanecen sólo en el recuerdo de ancianos y ancianas que, enterrados, ayudarán inconscientemente a incrementar el proceso de desecación cultural del viejo Mare Balearicus.

Puedo intuir la perplejidad del lector desde este lado del papel: ¿Cómo - se preguntará- pueden mantenerse semejantes afirmaciones de unas aguas tales que, desde el aire, se ven literalmente atestadas de todo tipo de embarcaciones? Aficionados, profesionales tal vez, pero no nuestros marineros. A pesar de moverse por los mismos medios, en idénticos mares; de navegar, de pescar, de conocer canales, corrientes, señales, se construyen en universos relacionales completamente distintos, determinados por un factor de separación superior y más intenso: son turistas, extranjeros, ciutadans. De ahí que, esencialmente, afronte la cuestión desde la perspectiva de las identidades diferenciales entre campesinos y pescadores.

\section{El MAR EN LA ANTROPOlOGÍA}

El mundo marinero como tal no ha sido, hasta hace algunos años, objeto central de la antropología. Conocemos algunas monografías que han tratado de los pescadores, de las migraciones marítimas o de las navegaciones desde el inicio mismo de la disciplina; pero casi siempre como parte integrante ( $\mathrm{y}$, por qué no decirlo, ineludible) de las relaciones económicas, culturales, simbólicas de un colectivo más amplio basado en alguna tierra, grande, pequeña, dispersa o concentrada, pero tierra a dentro al fin y al cabo. Malinowski en las Trobriand, Firth en Malaysia, Barth en el sudeste indio, incluso en cierta medida también Boas en la norteamérica kwakiwtl, nos hablan de intercambios, de universos mentales donde el mar y sus recursos juegan roles esenciales, imprescindibles. En L'esprit du don, el origen mismo de la interpretación adulta en la antropología moderna, el hau no podría existir sin la mar comunicadora, rompedora y generadora. Aunque, eso sí, casi siempre nuestros maestros etnólogos nos han hablado con los pies secos.

En el Estado Español tampoco abundan los tratamientos específicos del tema. Los estudiosos externos que, desde principios de siglo, vinieron a redescubrir el Sur, no se interesaron de forma central por los bous, las trainyes, los faluchos, los llaüts, los bots, gussi, las bateas o las dornas y los universos que a bordo de ellos o mediante su manejo se construían, reconstruían y manipulaban; buscaron las pequeñas comunidades campe- 
sinas, las monografías del aislamiento que, no sin aportar interesantes elementos de análisis al conocimiento antropológico, han coadyuvado a mantener una idea limitada y sumamente terrestre de nuestras culturas. Los padres de la disciplina en la Península Ibérica y aledaños no rompieron completamente con esa tradición.

Aún así no estamos huérfanos de datos; ni tan siquiera de estudios y análisis marineros ${ }^{2}$. En los últimos años autores tales como J. A. RubioArdanaz, 1994; J. M. Apalategui, 1984; Barandiarán, 1982, 1984; José Pascual, 1991; Y. Breton, $1981^{3}$, centrados fundamentalmente en el Atlántico, no sólo han comenzado a sistematizar la etnografía haliéutica a través de monografías, estudios de casos y análisis de aspectos y procesos en la pesca, sino que han construido ya elementos centralmente antropológicos dentro de la disciplina considerada en su globalidad. En el Mediterráneo, la etnografía (más aún que el análisis antropológico propiamente dicho) también aporta ejemplos interesantes. Informantes, historiadores, geógrafos, novelistas ajenos a nuestra disciplina como tal, han ido acumulando descripciones, recolecciones de hechos y narraciones; han catalogado tipos de embarcaciones, han dibujado y conservado aparejos, formas de navegación, sistemas de reparto de la pesca, de los botines, de las tareas a bordo y fuera de la mar. Pero seguimos sin tener una etnología marítima mediterránea, pensadora de la parte de la gente de mar que sólo puede ser entendida y explicada desde la mar.

Quizás la excepción de Sanmartín, 1982; Miquel, 1994; C. Siges, 1991; A. Moreno, 1995; P. Vilàs, $1984^{4}$ rompa en los últimos años esta carencia

2 Desde el propio Josep PLÀ, pasando por Anselm TuRmedA (S. XVIII), por acercarme más a nuestro espacio de análisis, han hablado de la mar Balear y del Mediterráneo en general.

3 J. A. Rubio-ARDANAz, La Antropología Marítima subdisciplina de la Antropología sociocultural: teoría y temas para una aproximación a la comunidad pescadora de Santurtzi (Bizkaia) (Bilbao: Universidad de Deusto, 1994); J. M. APALATEGui Begiristain, "Etnografía y antropología de los pueblos pesqueros. Un ejemplo: Euskal Herria", Coloquio de Etnografía Marítima, Museo do Pobo Galego (septiembre, 1984); F. BARANDIARÁN IRIZAR (ed), La comunidad de pescadores de bajura de Pasajes de San Juan (ayer y boy). Estudio antropológico (San Sebastián, 1982); José PASCUAL FERNÁNDEz, Antropología Marítima, bistoria ecología, organización social y cambio económico entre los pescadores (Madrid: MAPA, 1991); Y. BRETón, "L'Anthropologie sociale et les sociétés de pécheurs: Réflexions sur la naissance d'un sous-champ disciplinaire", Antbropologie et Sociétés, 5(1) (1981), pp. 7-27.

4 Ricardo SANMARTín ARCE, La Albufera $y$ sus bombres (Madrid: Akal, 1982); Alejandro MiQuel NovajRA, "La Albufera mallorquina: ¿Campesinos o pescadores?", Revista de Antropología Social,4 (1995), pp 43-56; C. SICHES CuADrA, "La pesca en el campo de Nijar", D. Provansal y P. Molina (eds.), Etnología de Andalucía Oriental (Barcelo- 
( $s$ i es que de tal se trata). Sanmartín, ya en los 80 nos ayudaba a embarrarnos, junto a sus peculiares pescadores de Albufera, en un universo distinto, marino sin duda, pero de un mar en alguna medida atrapado, rodeado y angustiado por la tierra circundante. Yo mismo, en las islas en las que ahora vivo, trabajo, investigo y que, en cierto modo, me han convertido en su dulce y condescendiente prisionero, palpo la misma paradoja que subyace a todo lo anterior; mejor dicho, en su paroxismo: pequeñas islas enraizadas en un mar cada vez más lejano.

\section{DOS MUNDOS SEPARADOS}

Cuando llegué al archipiélago por primera vez, en 1985, con la intención de realizar un estudio identitario centrado en la mar, me encontré con su sistemática ausencia. Nos rodeaba, había sido durante milenios el centro mismo del comercio, la pesca y la piratería mediterráneos occidentales; pero parecía haberse disipado como un fantasma, tan sólo aparecido en el pasado remoto de narraciones casi fundantes.

Sin embargo sabemos que las Islas Baleares fueron para, por y en el mar hasta muy entrado el siglo $x^{5}$. Aparte de algunos historiadores centrados en el xviII y las pequeñas (y siempre jugosas) historias locales, hay que acudir a los escritos del Archiduque Luis Salvador de Austria para tener una etnografía mínimamente sistemática de los mundos marineros baleares ${ }^{6}$. Parece como si, con la inmersión definitiva en el universo turístico, tan sólo los marcos identitarios campesinos.(pagesos) hubiesen pervivido como única historia referencial.

Pero hay más. Si miramos la geografía humana balear, comprobamos la escasez de enclaves marítimos: excepto las correspondientes capitales isleñas y unos pocos poblamientos, fundamentalmente en Mallorca, los mundos isleños aparecen doblemente aislados. La mar no relaciona tampoco a las cuatro componentes del archipiélago, más bien las separa ${ }^{7}$; de

na: Anthropos-Instituto de Estudios Almerienses, 1991); A. MORENO VIUDES, Relaciones económicas y sociales de producción de la pesca artesanal en Torrevieja (Alicante, España) (Torrevieja: Instituto Municipal de Cultura, 1995).

5 Particularmente Gonçal LÓPEZ NADAL, El corsarisme mallorqui a l'edat moderna (Palma de Mallorca: Quinze anys dels premis d'investigació Ciutat de Palma-Cultura fi de segle, 1987), pp. 21-39 y Carles MANERA, Comerç $i$ capital mercantil 1720-1800 (Palma de Mallorca: Consell Insular de Mallorca, 1988).

6 Archiduque Luis Salvador De Hasburgo-Lorena, Die Balearen in Wort und Bild Geschildert (Leipzig: Breckhaus, 1869-1891).

7 Ver tesis doctoral del autor: Alejandro MIQUEL NOVAJRA, "La construcción de la identidad balear desde las relaciones campesinas" (inédita) (ciclostilado en el Departa- 
ahí que Mallorca, Menorca y las Pitiusas (Eivissa y Formentera) se constituyan históricamente como ámbitos culturales y relacionales difícilmente definibles como unitarios: la idea grupal de Baleares tan sólo está en la concepción de una administración jacobina y provincialista, pero no en la realidad cultural de cada isla. Finalmente, la profusión de torres de vigilancia, la ubicación de las casas principales (de possessió, de lloc o de finca $)^{8}$ en terrenos altos protegidos de la costa, la presencia, también en las narraciones y etnohistorias locales, del miedo al corso, al turco y al moro (rondalles) hacen al mar aún más lejano y peligroso.

No obstante, junto a todo ello hay una larga memoria de comercio, de emigración, de contrabando, de navegación. Sóller, una pequeña villa del noroeste mallorquín, aislada durante siglos del resto de la isla por la mayor cadena montañosa del archipiélago, mantuvo hasta bien entrado el siglo XX una línea marítima directa con Sête y Marsella (hasta tres barcos semanales y, a veces, ni tan siquiera uno mensual con la capital, Palma). Los pilotos de Andratx (en el oeste de la Balear mayor) son conocidos aún por su pericia y destreza. Los formenterenses, siempre glosados como avezados marinos, se han adentrado tanto en la mar que, desde el XVIII, se han producido tres despoblamientos completos de la isla. Los bous, y sobre todo los llaüts mallorquines y menorquines y los falutxos pitiusos, vienen lanzando sus artes en el mar balear desde tiempos inmemoriales?. Sin embargo, los exiguos grupos que aún se construyen y relacionan en torno al Mare Nostrum viven en universos distintos, al margen (a menudo en el sentido estricto del término), ignorantes del mundo campesino e ignorados por éste.

En cifras de hace doce años (86-87) ${ }^{10}$, actualmente reducidas, los puestos de trabajo contabilizados en la pesca eran 1633 - con una población total de la provincia de 750.000 habitantes de derecho; el valor económico de las capturas (unos tres millones de $\mathrm{Kg}$ ) de poco más de 2.500 millones de pesetas y la participación en el PIB provincial del 0,5. De las 896 empresas censadas, el $87 \%$ eran familiares, basadas en la pesca artesanal o de artes menores, superando el $21 \%$ de las embarcaciones los veinte años de edad. A pesar de la notable mejora en el nivel de vida

mento de Antropología Social de la UCM, 1991). Ver también del mismo autor, $E l$ campo en la cabeza (Madrid: La Catarata, 1999).

8 Possessió es el nombre que recibe en Mallorca la gran propiedad de un senyor, absentista, regentada en régimen de arrendamiento o de a medias por un amo. Lloc es el equivalente menorquín. Finca es más genérico, exclusivo en Eivissa, y variable en el resto del archipiélago.

9 Embarcaciones artesanales mediterráneas.

10 Datos del Instituto Social de la Marina (1986). 
que incorpora la demanda turística, los ingresos no han permitido normalmente el salto adelante de la adquisición de nuevas embarcaciones, a no ser rompiendo el ciclo de herencia de la barca y mediante la constitución de pequeñas sociedades de copropietarios.

Parece como si la mejora relativa y absoluta que los campesinos mismos reconocen (ahora ya viven muy bien, mejor que nosotros) haya terminado por ser un nuevo factor añadido a la crisis del sector y del grupo de identidad en sí. Efectivamente, el mantenimiento de la pesca de siempre, como siempre la bemos becho tiene grandes dificultades de adaptación a las nuevas pesquerías y sistemas; los pescadores isleños compiten entre sí por un pescado escaso en un mar polucionado, esquilmado, con fondos difíciles repletos de pozas e irregularidades, pero son los "otros pescadores", los foráneos, con embarcaciones de mayor tonelaje, tecnologías punta y organizaciones del trabajo mucho más complejas, los que abastecen a los mercados baleares. Por último, la ausencia de industrias ligadas a la conservación y distribución reduce aún más la posibilidad de mantenimiento a largo plazo.

\section{LA PAGESIA: EL MARCO IDENTITARIO IMPERANTE}

La mayoría de la gente conoce estas islas desde tierra. Pocos las han visto desde la mar libre. Ahora bien: las costas de un litoral cambian enormemente vistas desde tierra a dentro o desde la mar. Por eso la toponimia de los navegantes coincide pocas veces con la toponimia de los terrestres ${ }^{11}$.

Esta descripción magistral y clarísima del gran escritor catalán resume a la perfección la situación que actualmente se constituye en las Baleares. Quizás con la excepción de Eivissa y Formentera, los efectivos humanos que componen el grupo pescador no coinciden ni sincrónica ni diacrónicamente con los del campesino; la movilidad entre uno y otro es extremadamente baja, apenas perceptible en casos aislados que, o se olvidan, o se explican por factores especiales o individualizados.

En la mentalidad campesina, base de gran parte del imaginario colectivo balear actual, el concepto mismo de "mar" es, si no abiertamente negativo, sí al menos separador; términos tales como "el gran subcons-

11 "La majoria de la gent coneix aquestes illes de la terra estant. Pocs les ban vistes des de la mar lliure. Ara bé: les costes d'un litoral canvien enormement vistes de terra estant o de mar estant. És per això que la toponimia dels navegants coincideix rares vegades amb la toponimia dels terrestres" Josep PLÀ, "De les Medes a les Balears", Illes Mediterrànies 1. (Barcelona: Llibres a mà.-41 Edicions Destino. Edicions 62, 1986), p. 16. 
ciente colectivo", "el mar es el mal" son manejados por escritores locales actuales para definir esta extraña relación ${ }^{12}$. Quizás estos juicios sobrepasen, en hipérbaton, la valoración grupal isleña, incluso la específicamente campesina; sin embargo los he traído aquí para atisbar una visión de lo que pretendo mostrar.

Lo cierto es que aún hoy en día oímos hablar comúnmente de sa marina para referirse a todo terreno improductivo, cercano o no a la costa, y por lo tanto negativo para el campesino. $\mathrm{Y}$ podemos escuchar cómo el mar "traía las invasiones, se llevaba a los emigrantes". Sin embargo también estos dos males, en sus versiones más modernas, han producido la reconocida riqueza actual (si bien muy discutible) de las islas: las fortunas de las migraciones con éxito en América y Francia y el turismo.

Pero ello no obsta para que el pescador, aún minoritario y separado, exista. Comparte la misma tierra de referencia en tanto la habita, pero no en tanto la trabaja y vive de ella ${ }^{13}$; se trata, desde la perspectiva identitaria del terrestre, de un personaje en cierto modo intermediario, que se mueve de uno a otro lado de un espacio liminal situado en la costa.

Las relaciones entre ambos no son conflictivas, porque según ellos mismos nos declaran, simplemente no existen. Con las pequeñas excepciones a las que he hecho referencia, lo cierto es que hallamos muy pocos casos en los que del campo se haya pasado a la pesca; prácticamente ninguno en sentido opuesto. Ambas formas de vida, por lo observado, documentado y declarado, se reproducen por herencia. Pero mientras en el caso campesino ésta trasmite y a menudo divide la propiedad terraria, la barca y los artes no son divisibles. Los sistemas de tenencia de la tierra en las islas varían de una a otra componente del archipiélago y aún en el seno de éstas; tanto en el caso de propiedad (minifundios y latifundios relativos) como en el de arrendamiento a medias o los muy específicos Alous menorquines ${ }^{14}$, el traspaso es tanto para los hijos de los propietarios como, casi siempre, para los del encargado de la explotación. Los bous y sobre todo los llaüts baleares pueden mantener ese mecanismo sólo muy parcialmente, tendiendo a expulsar hacia nuevas embarca-

12 Carlos Garrido, Mallorca Mágica (Palma de Mallorca: Moll, 1988), pp. 30 y ss.

13 Ver tesis doctoral del autor, op. cit.

14 Idem nota 13 y Camilo CELA CONDE, Capitalismo y campesinado en la isla de Mallorca, (Madrid: S. XXI, 1979). Este último libro, parte de la tesis doctoral del autor, defiende una posición minoritaria con respecto a la actual cultura del trabajo mallorquina, particularmente en relación a la cultura empresarial, pero que yo comparto y he comprobado a lo largo de mis trabajos de campo en el archipiélago: bajo desarrollo del industrialismo, inexistencia de la conciencia de la modernidad y mantenimiento de relaciones sociales e identitarias claramente agraristas. 
ciones los brazos excedentes. También, con la ruptura de los sistemas de bereu (heredero único) por la imposición de las legítimas en el código civil, por un lado, y con la excesiva subdivisión sucesiva de las parcelas en los casos de parts iguals por otro, los campesinos acaban siendo expulsados de su ámbito de vida, trabajo y religación; con una clara excepción: aquellos que obtuvieron parcelas de inútil marina costera han acabado por invertir el organigrama social intrafamiliar con la especulación turística. No obstante, tanto pescadores como pagesos progresivamente excedentes han venido a engrosar, primero, la emigración y, después, el Sector Servicios del archipiélago; el nuevo marco turístico, la economía monocroma y monocorde de las Baleares de hoy en día aparta progresivamente a unos y a otros de sus bases constitutivas, substituyendo cada vez más la realidad por la memoria, transformando la construcción de la identidad cotidiana en émulos practicados durante el tiempo de ocio.

El relativo particularismo que ha venido caracterizando a las componentes del archipiélago se rompe poco a poco por la unificación de la actividad hotelera; sin embargo sigue perviviendo aún en los referentes simbólicos e históricos de cada espacio isleño. Por lo tanto hablaré de cada isla situando las especificidades distintivas, pero también avanzando a través de ellas en aquellas bases que, reconocidas o no por sus protagonistas, les son comunes.

\section{MALLORCA: EL MAR ENTERRADO}

Las afirmaciones que acabo de realizar no se corresponden completamente con todas las realidades baleares concretas; mejor dicho, los niveles de ruptura o integración, de compartimiento o segregación entre marineros y campesinos varían con los espacios de referencia.

Mallorca presenta la mayor diversificación interna, también, en esta cuestión ${ }^{15}$. En cualquier caso, y en líneas generales, la categoría <pescador $>$ interviene en la identidad mallorquina (ampliamente campesina, con independencia del pequeño papel que el primario juega actualmente en el PIB) como un factor externo. Inclusive en los municipios con mayor porcentaje de costa y un renovado contacto con el mar a través del turismo como mediador, el marinero no forma parte de los referentes de pertenencia grupal. Aún en su más directa e inmediata concreción, la de pescadores de bajura, las agrupaciones humanas que viven en y del mar son mantenidas fuera de la mallorquinidad esencial: "aunque padeciesen

15 Tesis doctoral op. cit. 
necesidad, no hacían de pescadores; se iban por la montaña, de roteros, de carboneros... nunca de pescadores" ${ }^{16}$. La negación del paso a la pesca del campesino esencial se complementa y refuerza con la categorización negativa de los pescadores, a los que se llega a definir "como basureros, lo más bajo que había".

Como se verá, a lo largo de toda mi exposición aparecen el pasado y el presente entremezclados, alternados, sin aparente lógica: ésta realmente subyace al hecho de que, mientras lo que se tiene que analizar y sobre lo que se construyen opiniones son realidades socioeconómicas, los mecanismos y valores de análisis y de comparación son los propios de la construcción identitaria; para el grupo que opina y para el objeto opinado.

Un ejemplo claro lo tenemos en el consumo de pescado: la proteína más accesible (y pensemos en los duros tiempos de la posguerra) prácticamente, excepción hecha del gerret, la llampuga en su temporada y espacios de tradición y la anguila en el específico ámbito de Sa Pobla, está ausente de la mesa mallorquina ${ }^{17}$. Según los libros de cocina del XVIII y el XIX, no siempre ha sido así (aunque es habitual oír decir que se trataba de comida de señor), y la actual demanda turística también viene a situarlo en un nivel importante en el mercado. Aparte de la piscifobia inferible, hay que tener presente que el pescado es también la sinécdoque del pescador mismo: el consumidor de pescado, de esa manera, se alejaría del ser campesino.

Los poblamientos también presentan características diferenciales reseñables. Para empezar se hallan alejados de los de estructura primigeniamente campesina que, a su vez, supone la base constitutiva de las villas de mayor tamaño. Estas poblaciones costeras, respecto a la cuales se afirma desde el universo pagès que "las casas pescadoras siempre han existido" pero que "las colonias se han ido constituyendo", varían mucho en sus mecanismos y formas de aparición. Palma, sin duda el puerto más importante del archipiélago, alberga la mayor colonia marinera; pero se trata de la gran capital, de Ciutat por antonomasia. Siendo, como el resto de centros administrativos isleños, una síntesis de las diversas agrupaciones que se han ido constituyendo en su territorio, nos ofrece aún hoy en día barrios abiertamente identificados con la marinería: Santa Catalina, ya inmerso casi

16 Todas las declaraciones entre comillas han sido recogidas personalmente entre las personas que habitan las zonas tratadas.

17 El primero suele ser consumido en coques, especie de empanadas abiertas, con verduras, en casi toda la isla; el segundo, de temporada, sólo en los espacios donde se pesca (norte); el tercero prácticamente sólo en Sa Pobla, guisado o en coca. 
en el mismo centro urbano, reniega de las fiestas patronales capitalinas (San Sebastián, a finales de enero) para seguir marcándose y definiéndose sólo a través de su Sant Pere (San Pedro). El porcentaje de pescadores activos que lo habitan es mínimo, pero su historia identitaria se sitúa con claridad en ese ámbito de definición. Los escars, pequeños abrigos construidos en la costa baja de roca, nos marcan los viejos caladeros provisionales que han terminado por convertirse en auténticos pueblos, a menudo, tendentes a la independencia con respecto a los municipios (casi siempre en el interior) madre.

\subsection{Toda afirmación taxativa pierde contacto con la heteronomia vital. La Albufera}

Existe una primera y clara excepción en el este de la isla: la Albufera. Conviene recordar aquí algunos de los elementos centrales que ayudan a constituirla como marco de un síndrome específico. Se trata de un relativamente amplio espacio anfibio, en el este de la isla, conectado con el mar a través de una gran laguna. Rico en especies cinegéticas y piscícolas hasta mediados de siglo (ahora recupera parte de su esplendor al haber sido declarado Parque Natural), se convirtió durante el XIX y parte del Xx en la base del cultivo de arroz, de verduras y también de una específica forma de pescar. De manera análoga a la que nos narra Sanmartín con respecto a Valencia, la base poblacional que actúa en su interior también es campesina. Pero, a diferencia de lo que allí acontece, en el aiguamoll mallorquín no pierde nunca su raíz ni su identidad agrícola para especializarse en la captura de peces.

De hecho dos de los municipios más centralmente campesinos de la isla, Sa Pobla y Muro, son los que se lo apropian con exclusividad. Incluso lo manejan en la construcción de sus identidades campesinas; pero también en sus diferenciaciones internas cuando así lo necesitan. Los habitantes de Sa Pobla, uno de los pocos municipios centrados aún en el cultivo de la patata de exportación, se autodefinen como "pescadores de Albufera" precisamente para marcar las diferencias con sus vecinos de Muro. Ahora bien, ni los unos ni los otros permiten entrar en el campo de definición a los pescadores de mar, en la vecina Alcúdia, en la costa: éstos siguen siendo ajenos al universo en torno al cual construyen su identidad.

El sistema de pesca en la Albufera, de manera similar a la valenciana, se basaba en la subasta, normalmente por cuatro años, de la totalidad de la pesquería. El mecanismo de redolins descrito en La Albufera y sus Hombres, sólo se producía en el caso mallorquín como resultado de 
subarrendamientos o colaboraciones posteriores. El hecho de que la Albufera haya sido casi siempre de propiedad privada ha impedido un reparto similar al del levante peninsular; pero también ha supuesto un obstáculo para la especialización de dedicación que allí se produce: en Mallorca el pescador buferer lo era tan sólo mientras duraba la temporada y mantenía la concesión, sin descuidar, a nivel familiar, el cultivo de sus tierras.

Ello no obsta para que reconozcamos ámbitos de trabajo y de su reparto característicos, no sólo de la pesca balear, sino prácticamente de toda la desarrollada en el Mediterráneo noroccidental. Cuando el campesino-pescador tiene la concesión de la pesquería de la Albufera tiende a vivir en su ribera durante la temporada alta que, al concretarse fundamentalmente en la captura de anguilas, se desarrolla en torno a los meses invernales. Las mujeres de la familia reciben el pescado y se encargan de su venta. Pero aquí vuelven a surgir las diferencias: mientras estas últimas reciben entre los "otros" pescadores el nombre de patrona como correspondiente femenino al patró, dueño o patrón de la embarcación o el arte, en nuestro caso mantienen la denominación de madona (la mujer principal en la casa campesina) o madó (cuando su relación es secundaria, es decir no ligada al explotador principal o al propietario-agricultor), como femenino de l'amo (propietario-agricultor, explotador, encargado de la finca). Por tanto, lejos de romper en el sutil y manipulable terreno de la denominación con el universo campesino, lo refuerza y afirma.

El campesino-pescador utiliza sin duda referentes pescadores, pero los substrae de la categoría <pescador $>$ para apropiárselos como factores de religación, de fortalecimiento de pertenencias específicamente internas frente a otros grupos campesinos. Como he indicado, la pesca más importante en la Albufera es la de la anguila. Pues bien, casi como un rocambolesco e inconsciente tour de force a las Abominaciones del Levítico, donde sabemos que la anguila resulta ser impura frente al pez escamado, la especie lucífuga es incorporada, en toda su pureza diferencial, al mundo pagès en oposición a la mayoría de teleósteos - peix d'escata- propios de los "otros" pescadores. Más aún, en un universo alimentario basado en el cerdo, la anguila adquiere categoría de campesinidad prioritaria sin por ello introducir contradicción alguna.

La metáfora vicaria adquiere cuerpo social en el enfrentamiento fronterizo: en Es Lago Esperança, la mayor extensión acuática que linda con el mar, se producen las acusaciones de robo de pesca. Sí, los campesinos llegan a acusar de ladrones de pescado a los pescadores. Incluso los artes de unos y de otros difieren: moredells, pesca de cuc, a l'encesa, frente a trasmalls, bolitxos, arts de platja, volantí e incluso fluixa. 
Existen tres factores esenciales que nos ayudan a entender mejor esta situación:

1. La actividad pesquera en S'Albufera ya sólo puede situarse en el pasado; un tiempo, que, como sabemos los antropólogos (y no pocos políticos), es utilísimo en la manipulación referencial e identitaria.

2. La práctica del oficio de pescador es común a los campesinospescadores y a los marineros de la costa; sin embargo la esencia definitorial que comporta no actúa ni de la misma forma ni, mucho menos, en la misma medida. El grupo campesino (pagès) domina los elementos mediante los que se articula el eje identificador del grupo pescador. Éste, compuesto por (en términos campesinos) pobres, es decir los que no poseen o no tienen acceso a la tierra, no tiene otro recurso que el pescar, hasta el punto que se pueden ver constreñidos a "robar la pesca albufereña de los campesinos". En pocas palabras, mientras los campesinos-pescadores no dejan de ser campesinos y siguen definiéndose en función de la tierra y de las relaciones instituidas en torno a ella, los pescadores sólo lo pueden hacer mediante su oficio de exclusividad.

3. El tercer factor sesga la contraposición campesino/pescador, ya que identifica, desde los dos pueblos ya mencionados, Sa Pobla y Muro, a la vecina Alcúdia con la matriz del grupo pescador excluido. Es decir, se usa el diferencial pescador/campesino para reafirmar el propio espacio frente al ajeno.

\subsection{Los pescadores de mar y los campesinos de ribera}

Las relaciones que se establecen entre los campesinos cuyas vidas y tareas están más próximas a la costa y los pescadores, manifiestan de manera más clara y al tiempo más contradictoria esa exclusión en el terreno identitario. Es obvio que ambos grupos (grupalidad en principio tan sólo analítica, pues la realidad convivencial es más dialéctica) comparten espacios polirelacionales tales como el pueblo, pero también otros más difícilmente diferenciables como la comunidad de ámbitos de construcción de significados ${ }^{18}$. Aquí, al contrario de lo que nos explicaban los campesinos de tierra adentro ( $y$, recordemos, este concepto es siempre función del espacio total disponible en una isla relativamente pequeña), no es impensable que los hombres enraizados en el agro pesquen de vez en cuando o inclusive se pasen a la pesca. Para poder explicar tal hecho sin romper los argumentos agraristas, se acude a matices que adquieren más

18 Umberto ECO, La estructura ausente. Introducción a la semiótica (Barcelona: Lumen, 1968), pp. 81-84. 
importancia de la que, en principio, parecen tener "a lo mejor, si lo necesitaban, iban a la pesca en temporada de langosta". La langosta, una especialización de captura que sólo se ha desarrollado plenamente a partir del nacimiento de la demanda turística, actúa de esta manera como amortiguador de la salida relacional que supone el campesino pobre enrolado en un bou o una llagostera ${ }^{19}$.

Pero, en cualquier caso, volvemos a lo mencionado anteriormente: el campesino mallorquín se define por el espacio y las relaciones, tanto inmediatas como acumuladas, mientras que el pescador lo hace centralmente en función de su oficio. La frase "Cuando ya habían acabado las faenas, iban a pescar en la temporada, cuando ya habían trillado" es un claro ejemplo de lo que acabo de afirmar.

Sin embargo, si no se plantean situaciones contemporáneas y nos acercamos a los procesos de construcción de la identidad mallorquina desde la perspectiva histórica, los pescadores son asumidos plenamente como parte integrada. Desde la oposición de los pescadores propios con respecto a los marineros de yates, pasando por las afirmaciones tipo unuestros pescadores han sido siempre los mejores y los más arriesgados", hasta llegar a la tradición marítima como mecanismo de máxima evidencia de la historia diferencial mallorquina, el pasado viene a substituir en positivo lo que en el presente es negativo.

Un caso opuesto al de la Albufera, en el sentido de la apropiación no contradictoria de definidores pescadores por parte de campesinos, es el del Port (puerto) de Sóller, villa que he mencionado con anterioridad. El enclave poblacional principal, como ocurre casi siempre en la isla, está alejado del mar, situado entre montañas; sin embargo su zona portuaria es de las más antiguas de Mallorca; se trata de un "barrio" que "está apartado a causa de la mar, a causa de la pescan. El alejamiento físico, pero fundamentalmente relacional, es causa del oficio de pescador. En otro de los espacios con puerto propio y relativamente antiguo, Porto Cristo, en la costa de levante, que actualmente reivindica su condición marítima en función de la deseada segregación del Municipio (con "capital" interior) de Manacor, incluso se llega a afirmar que los bares frecuentados por campesinos y por pescadores no solían ser los mismos y que, en caso contrario, las tensiones siempre estaban a flor de piel ya que, entre unos

19 El Llaüt es el nombre que recibe el llagut catalán en Baleares. Su tamaño es variable, así como sus formas, teniéndolos desde con popa lanzada hasta con popa de espejo; en principio llevaba una gran vela latina, muy picuda, actualmente substituida por motor. La pastera es la patera andaluza, de fondo plano; el bot es un bote, también de tamaño mediano, muy utilizado en Eivissa. Bou, finalmente, es el término con el que se conoce a los arrasteros, en principio en parejas, del Mediterráneo occidental. 
y otros "no se entienden". Según los campesinos y ciudadanos locales, los pescadores "tienen una manera muy peculiar de ser", una "idiosincrasia distintan.

Muchos de los colectivos de pescadores no difieren de manera importante de las opiniones terrestres. En la zona de Sóller llegan a reconocer que algunos de sus miembros provienen de antiguas familias de campo cuyas posibilidades de mantenerse mediante el cultivo en tierras en propiedad, por arrendamiento o como peones llegó a hacerse imposible. El oficio de la pesca, así, tiene más de última opción que de tradición marinera; tan sólo el incremento de la demanda turística (gamba, langosta, especies prohibitivas antes del boom) lo ha hecho mínimamente rentable y lo ha dignificado socialmente. Pero las razones de esa coincidencia de criterios entre la gente de mar y la de tierra sólo se produce en los términos y en el discurso aparentes; en la semiótica subyacente existe un distinto hilvanado de significaciones. Como ya dije en otro lugar ${ }^{20}$, en el universo agrarista isleño pervive con fuerza el valor del trabajo duro y sacrificado situándose por encima del de la rentabilidad productiva de la tierra; al menos a nivel identitario. Entre los pescadores sucede de igual manera aunque, claro está, cambian los referentes: a pesar del ámbito de marginación con respecto al resto de los isleños, de la miseria que empuja al oficio de la pesca, éste se mantiene por fidelidad y por actitud. El campesino - para el pescador - vive en una riqueza comparativa, en la seguridad; sólo el abandono de la lealtad a su oficio por reducción de beneficios y la superior expectativa creada por el incremento de la demanda piscífaga del turismo, le han empujado a empuñar los artes.

De esta manera el pescador de oficio y tradición mallorquín se presenta a sí mismo en un nivel moral superior con respecto a los recién llegados. Un discurso similar se lleva a cabo en relación a la otra salida estructural del grupo (esta vez común al campesino) hacia la hostelería: la gente pescadora, afirman, no es la gente que va de hoteles. Para reforzar esta idea los propios protagonistas no dudan en acudir a un razonamiento abiertamente contradictorio: el pescador está muchas horas en la mar, pero no siempre trabaja; pasa horas y horas tumbado hasta llegar a la pesquería; un pescador al que pusiesen a trabajar (en la hostelería) no sobreviviria.

Sin embargo la esencia de esa diferenciación tiene una base más intensa: el campesino puede cambiar más fácilmente de trabajo porque está "atado" - lo que supone "su seguridad" desde la otra perspectiva- al espacio; el pescador carece de espacio-tierra de pertenencia, y por lo tanto

20 Tesis doctoral A. MiQuel, op. cit., pp. 380 y ss. 
tiene que seguir haciendo de pescador para ser pescador, lo que, en el terreno de la identidad, equivale simplemente a ser.

Si nos adentramos directamente en el seno del universo relacional pescador y no lo observamos bajo el prisma de la mirada pagesa, podemos comprobar cómo la unidad no territorial que ésta nos mostraba desaparece, desgajándose dialécticamente por el mismo sistema de la fusión (frente a necesidades de identificación con respecto a un exterior común) y la fisión (separación en las relaciones inter pares). Sin duda esto acontece en los pueblos o enclaves costeros de referencia, pero fundamentalmente en el "territorio" que les es propio en exclusiva: la mar.

El mecanismo, conocido en todo mundo marinero organizado, es el de la división del espacio marino en pesquerías; o, en términos emic, en pesqueres. Los pescadores artesanales de cada puerto suelen pescar en su zona (pesquera), aunque no haya ningún acuerdo previo al respecto: mantiene, también en el desarrollo del oficio, el marco espacial terrestre como referencia. Pero ese espacio de pertenencia que tanta fuerza adquiere en la construcción de la identidad campesina, es tan sólo una segunda instancia en la pescadora que se añade a la inclusión grupal. "Un pescador se entiende mejor con un pescador que con un pagès" $O$ "en la mar todos son amigos, no hay enemigos..., cualquier pescador que venga de cualquier puerto", son frases que resumen la presentación hacia el exterior del pescador mallorquín. Ahora bien, las rupturas y los enfrentamientos, como no era menos esperar, se producen: con respecto a los pescadores peninsulares, de otros países del Mediterráneo, pero también entre islas y puertos de la misma isla.

No obstante hay que hacer una salvedad, aparentemente contradictoria, pero coherente con el papel marginal del pescador en la identidad mallorquina persistente. El foraster, ni más ni menos que el forastero en términos estrictamente lingüísticos, es mucho más en la sociolingüística y en la etnolingüística mallorquina: peninsular de habla castellana, emigrante y empleado por cuenta ajena. Su entrada en el universo isleño se produce antes del boom turístico, precisamente en el ámbito agrario; posteriormente la hostelería llega a convertirlo en un (al menos a nivel identitario) «terrible competidor" con el mallorquín de socarrel (lit. de máximo enraizamiento). Respecto a esta figura existe un nivel de rechazo, no siempre explícito, pero que en cualquier caso lo aparta de roles centrales en el mundo simbólico propio: jamás un foraster ha llegado a ser amo de finca - la microhistoria, como siempre, desmiente la historia identitaria-. Sin embargo su entrada en barcos de pesca, inclusive como patrón, no ha presentado nunca problemas importantes. La marginación, la miseria esencial del pescador, los equipara; pero fundamentalmente lo hace la base socioeconómica que retiene 
al campesino en una red de clientelismo, herencia y derivación genealógica, que no atrapa al marinero. En la actualidad más inmediata los marroquíes, cabezas de turco de la crisis estructural agrícola que ayudan centralmente a paliar, empiezan (como en el XVIII y el XIX) a faenar en el más claro oficio común de las dos riberas mediterráneas.

\subsection{Los nuevos pueblos, la organización familiar campesina y pescadora: paralelismos y diferencias}

El campesino ve con malos ojos el desgajamiento efectivo de los asentamientos originariamente pescadores; a estos efectos sí se trata de sus pescadores. Pero los movimientos secesionistas que actualmente se producen, distan mucho de basarse en los grupos marineros, aunque se busque en ese específico carácter la nueva identidad reivindicativa. Para los pollensines, en el noroeste, los pescadores eran de Pollença, pero abora se ban becho molleros (de Eu Moll, como se refieren a la zona portuaria de la villa); es su oficio el que los separa de la primigenia pertenencia espacial. El campesino, cuando acababa sus tareas, se acercaba al espacio controlado de la mar, a la playa, para lavar a las bestias y hacer un rato la familia, pero siempre tenía muy clara su religación esencial.

El grupo pescador también utiliza (cabe decir que apoyado por no pescadores con propiedades hoteleras en la costa) la endohistoria para reivindicarse. Los mitos fundantes, esenciales en este combate de identidades, suelen de hecho tener al menos dos colectivos que intentan apropiárselos en exclusiva. Tras hablar del 100 aniversario de la fecha histórica en que se funda Porto Cristo (municipio de Manacor), un articulista local nos dice que, en medio de una gran tempestad "llegó a nuestras costas una nave que nadie sabía de dónde venía y a dónde iba... paró al momento la tempestad y la nave por sí sola y sin guía se quedó parada frente a Porto Cristo y Dios quiso que fuese un regalo para Manacor $\left.{ }^{21}\right)$; los pescadores locales reivindican la imagen del cristo, "la mayor joya de Manacor, como algo propio: si, comentan no sin cierto excepticismo (la religiosidad pescadora es muy diferente de la campesina), la barca arribó a nuestras costas, nuestra es la imagen y su significación; nuestro puerto. En Cala Rajada, más al este, es una virgen la que hace el mismo recorrido físico (ayuntamiento de Capdepera) e identitario.

En otros casos son las fiestas, a menudo reinterpretadas desde los respectivos ports, las que simbolizan y celebran el diferencial espacial. La

21 P. MARCH, Manacor Comarcal, 30 de abril de 1988. 
festa $d u$ pi (fiesta del pino, un "mayo" primaveral de Pollença), tiende a repetirse con variantes en el puerto; el caso del barrio de Santa Catalina, en Palma, ya comentado, con la negación del patrón global y la reivindicación del específico; las fiestas de Moros i pagesos (no "cristianos", sino específicamente campesinos) en Sóller y Pollença, donde los habitantes del puerto, máxime si son pescadores, suelen cubrir plurigeneracionalmente los papeles de moro; recientes sardinades en los barrios portuarios frente a las clásicas torrades de carn (parrilladas de cerdo) en el interior. No es extraño, por lo tanto, ver invertida la ya conocida explicación de la invasión marina, situándose al terrestre como invasor, inclusive como pervertidor del carácter marinero e introductor de la especulación turística (Cala Rajada frente a Capdepera, ésta frente a Artà, etc.).

La opinión de tierra adentro aprovecha una realidad histórica admitida por los pescadores mismos: los nuevos espacios son resultado de asentamientos paulatinos de pescadores de antiguo: Porto Cristo, pero fundamentalmente Cala Rajada, seguramente el segundo puerto en la exigua pesca mallorquina, es resultado de la acumulación de viajes de invernada de pescadores valldemossins (integrados en una misma cofradía con Sóller y Deià). No es, (para aquellos, pero sí para éstos) un espacio fundado, sino derivado. Pero el pueblo es, en cualquier caso, siempre un espacio compartido. A los mecanismos de fusión o desgajamiento identitario en función de la oposición circunstancial o estructural, se superpone el ámbito de la pertenencia construida en torno al oficio (pescadora) o a la tierra (campesina). En el pueblo la tierra no es tal, sino la casa, el huerto, espacios cuyos habitantes y/o propietarios pueden ser miembros de cualquier grupo (incluido, y cada vez con más densidad, el extranjero); pero sobre todo el pueblo es el mundo del intercambio, del mercado, de la lonja ${ }^{22}$ : es el espacio de encuentro.

El concepto y conformación de la familia, como hemos visto antes, sigue pautas paralelas en uno y en otro grupo: el hombre continúa siendo el definidor grupal externo también entre los pescadores. En el sur (Palma fundamentalmente), también son ellos los que cosen las redes; en el norte (Sóller y Valldemossa) a menudo lo hacen las mujeres junto a los hijos pequeños. Pero lo mismo que la mujer campesina, sa madona, no ejerce las tareas centrales en el campo, sa patrona ni tan siquiera debe subir a la barca: "la barca no es para la mujer" "Las mujeres ipescar? ¡No las queremos ver nunca!n. Incluso aún hoy en día he podido observar como pervive la idea de mala suerte ligada a la presencia de la mujer embarcada "Yo no lo creo, pero no se sabe nunca... por si acaso más vale que

22 Prácticamente inexistente en las islas, excepción hecha de Palma, Maó y alguna pequeña en algún pueblo de muy reciente creación. 
no", me comenta un joven pescador de Porto Cristo; y, recordemos, la suerte es un factor prácticamente estructural en el universo simbólico marinero. Las mujeres sin embargo tienen un control superior al declarado, ya que son ellas, ses patrones, las que venden el pescado, pero también, al igual que en el mundo campesino, las primeras que salen de su grupo de pertenencia para entrar en las pequeñas industrias locales y en la hostelería: a pesar del análisis etic, son más prescindibles.

\section{MENORCA: EL MAR SEPARADO}

La específica agricultura menorquina, basada en grandes propiedades (llocs) ${ }^{23}$ dedicadas desde hace años al monocultivo bovino, mantiene al campesino isleño más encerrado en el agro que cualquier otro del archipiélago. Por añadidura, la mejor adaptación de la producción agraria a los cambios económicos y su directa interrelación con una floreciente industria de productos lácteos, hace que la figura campesina esté más cerca de la realidad socioeconómica y no sólo en el marco identitario. La menor incidencia relativa del turismo, finalmente, sostiene las estructuras sociales dentro de un espacio más domeñable y cognoscible por sus protagonistas.

Con costas mayoritariamente abruptas y escarpadas, presenta pocos puntos idóneos para la constitución de espacios que faciliten el contacto tierra-mar. Las playas de dimensiones más amplias tampoco han dado lugar a enclaves pesqueros: la conocida exposición a la invasión y la debilidad de las posibles defensas suelen estar en la base de la explicación emic. Prácticamente el único pueblo (no barrio de otro pueblo o ciudad) pescador propiamente dicho es Fornells, en la vertiente norte de la isla. Otras radas o calas, como Es Grao o Cala Tirant, se relacionan más con el turismo pujante que con la pesca profesional.

Ni la gran ensenada de Maó ni el estrecho entrante de Ciutadella responden a estas características; ambos, de hecho, constituyen las dos referencias (a menudo dicotómicas también por lo que respecta a la mar) pescadoras principales. En el sudeste Cales Font, en Sant Lluis, y otros más al sur y al este, son asentamientos de significación polivalente donde el grupo pescador comparte e incluso "cede" significantes propios al heterogéneo grupo "turista". A ello cabe añadir dos observaciones propias de la etnogeografía: la dimensión de la isla reduce las distancias entre las costas y el centro (nunca superiores a los $20 \mathrm{Km}$ ), favoreciendo la interrelación ente el pescador y el aterrestren; la escasa diferenciación orográfica (la única altura destacable tiene

23 Tesis Doctoral, A. Miquel, op. cit., pp. 900 y ss. 
unos $300 \mathrm{~m}$ ) reduce los apoyos físico-naturales a la diferenciación cultural. Pero la primera más bien lo que tiende es a generalizar el distanciamiento, mientras que la segunda se patentiza culturalmente en una homogeneización tal de las actividades pecuarias que agrupa a la mayoría identitaria frente a las identidades costeras.

\subsection{Puntos de vista}

A mi me parece que los dos trabajos son duros, pero pienso que el nuestro lo es más; ahora bien, el del pescador es más peligroso. Pero me pienso que hacemos más horas de las que hacen ellos. Lo que tienen es eso: el peligro de la mar.

El amo de lloc nos devuelve un argumento ya explicado: el oficio define centralmente al pescador; el campesino construye su identidad con otros definidores previos. Sin embargo, al situarnos en el ámbito de las identidades comparadas, vemos como el valor moral trabajo=sacrificio se sitúa en un marco de clara competencia entre ambos colectivos. Sabemos que el campesino menorquín se halla más atado a la tierra debido a las labores específicas del monocultivo dominante; ello supone más tiempo de trabajo, por ende un superior sacrificio, pero también una superior seguridad. Por contra, el pescador se realiza, faena, en oposición al principio de pertenencia espacial; como contrapartida carece de la tranquilidad relativa del mundo agrícola, ya que, al introducirse en el mar, el ámbito de la no pertenencia, de lo no dominado, debe convivir con el peligro. Si a primera vista este juicio emitido desde la perspectiva terrestre podría parecer un factor de "reducción de identidad", debe advertirse que esa seguridad es la meta del campesino mismo; pero, además, el peligro del pescador no es elegido, sino producto de la pobreza, de la ausencia de propiedad o religación con la tierra que le impele, históricamente (una etnohistoria, una vez más, centralmente campesina) a serlo.

Aún más, el peligro, como demuestran los mayores ingresos actuales del pescador, puede ser reducido e incluso evitado en la actualidad (no salir con mal tiempo, etc.), pero el riesgo del campesino que puede perder todo lo invertido ante una tramuntanada o un mal año, es inherente a su esencia misma: de hecho, para seguir siéndolo, debe mantenerse ligado a la tierra con todas sus consecuencias.

El grupo pescador categoriza de manera paralela al campesino: el trabajo en el campo es duro: "hay temporadas en que es peor que la langostan. En definitiva, se mantiene la separación sin negativizar definitivamente a la parte opuesta: "cada uno tiene su oficio: los campesinos en tierra y los pescadores en la mar. 
Las valoraciones morales no se restringen, obviamente, a las características genéricas de los modi vivendi de cada grupo, sino que entran sin solución de continuidad en el carácter atribuido y directamente relacionado con aquellos. Los pescadores son festivos; llegan a puerto y, al haber acabado la tarea, beben, arman jaleo: "cuando vienen de pescar, ya están listos y nosotros no acabamos nunca" Los campesinos son cerrados, huyen de la modernidad, tienen sus mundos exclusivamente centrados en sus fincas. Sin embargo los actuales movimientos de unos y otros, fundamentalmente en el pueblo, el (recordemos) espacio de encuentro, reduce las distancias categoriales: "ahora, con los coches, ya viven como nosotros, como un pescador".

\subsection{Espacios y matrimonios: lo común y lo exclusivo}

El pueblo, como vimos en Mallorca, es un espacio compartido; sin embargo ello no es óbice para que, a pesar de la mayor homogeneidad de la Balear menor, aquí, esta vez en forma diferente a la mallorquina, se establezca una cierta distancia referencial: los campesinos con una dimensión espacial exclusivamente interna y los que basan ésta en los diacríticos costa/interior. Los primeros se religan a los pueblos de Es Mercadal, Ferreries y Alaior, los segundos al resto de municipios; sin embargo determinados barrios, lloguerets (algo menos que aldeas) de los últimos, ejercen la misma función "apartadora" de los anteriores. Si bien es cierto que la entrada del turismo, la mejora y extensión de las vías y medios de comunicación han reducido también las distancias relacionales, no debemos olvidar que, a nivel de identidades, éstas persisten: "antes, cuando no había turistas, casi todo el mundo estaba casado familia con familia, la hija de un pescador con un pescador; ahora ya no tanto, pero algo hay". Lo cierto es que, en los matrimonios mixtos que he podido conocer, si la esposa era de proveniencia campesina, se definía como filla de pagès. El caso contrario es sin duda más difícil: primero, porque los llocs cercanos a la costa son, por su extensión, pocos y por lo tanto la disponibilidad de mujeres es muy reducida; segundo, porque el campesino que pretenda seguir siéndolo "necesita" una mujer de campo desde la perspectiva de un sistema de producción aún hoy en día basado en gran medida en la familia y la división sexual del trabajo. Si el emparejamiento es inverso, por lo conocido respecto a la movilidad de oficios y a la escasez cuando no nulidad de barcos de pesca disponibles, así como por la inhabilitación cultural de la mujer para ser pescadora, no se continuará la saga marinera; en el campo, la entrada de un marinero sería harto difícil 
por los mismos motivos aducidos, además de por el rol femenino en las jerarquías agrarias.

Los pueblos en sí mismos también mantienen identidades predominantes: los pagesos de lloc de los alrededores de Fornells prefieren recorrer más distancia hasta la sede del ayuntamiento, Es Mercadal, acercándose al centro pesquero tan sólo para ir a misa. Las fiestas de celebración del pueblo como tal, son casi siempre dobles; en el caso de Fornells, la Virgen del Carmen, que es sólo para ellos, para los pescadores, y Sant Antonio Abad, la fiesta del pueblo, durante la cual hay pescadores que incluso faenan. El mito fundante del pueblo, una vez más una Virgen llegada en barca sin piloto durante una tormenta, también se articula diferencialmente según se obtenga la explicación desde el terrestre o desde el hombre de mar. Pero quizás el ejemplo más evidente sea el de la Colcada de Sant Joan, durante las fiestas de San Juan en Ciutadella. Se trata de un imbricado y complejo conjunto de protocolos y normas tales en las que sólo las personas ligadas directamente al campo pueden participar y ser miembros de la junta rectora y organizadora (caixers); durante su desarrollo se representan las jerarquías "ideales" del agro menorquín y la preponderancia "deseada" de éste sobre el pueblo. Si los no campesinos no pueden jugar los roles principales, los pescadores están abierta y explícitamente excluidos. Actualmente, durante el desarrollo de la fiesta, estos últimos invierten la relación festiva y ejercen de celebrantes desde el público.

\subsection{Reorganización de los sistemas de valores}

He estado hablando a lo largo de las páginas anteriores de identidades diferenciadas, de significantes (categorías y valores con un significado específicamente articulado en torno a una concreta identidad) no intercambiables; sin embargo la necesidad de convivencia en un espacio pequeño tal como es una isla, máxime cuando la modernidad, a través del turismo, ha irrumpido con fuerza y velocidades insospechadas hace tan sólo veinte o veinticinco años, exige una comunidad de códigos y una gran capacidad de adaptación mutua y con respecto al exterior interiorizado.

Para empezar la relación mar/tierra tiene que tender a la contigüidad. $\mathrm{Y}$, efectivamente, lo que antes era como máximo acercarse a la costa a "pescar con una cañita", ya se ha transformado en que "ahora ya hay muchos pagesos que ya tienen su barquitan; claro que, como apostillan los pescadores, "de recreo, para pasearse un poco y coger algún pez". La entrada en el mar de quien lo temía, lo rechazaba como parte del paisaje 
de su vida cotidiana, se lee más en clave de ocio, de incremento de bienestar, que de transmutación valorativa. Por otra parte, los pescadores, con ingresos más seguros que los de antaño, se acercan a la tierra; en cierto modo, también de "recreo": "si conoces mucho a un pagès, a lo mejor te deja unos metros de huerto para hacer unos tomates y eso para pasar un ratom. El acceso a la propiedad o a la regencia de un lloc, sigue alejado. Con todo, las distancias estructurales en tanto grupos permanecen, ya que, como los protagonistas mismos muestran, el traspaso es tan sólo individual.

Comentaba en otro lugar ${ }^{24}$, siguiendo etnografías bien conocidas, que en una estructura socio cultural basada en mayor o en menor medida en la división de espacios y actividades por sexo y edad, las posibles transgresiones categoriales y grupales no son tales precisamente en función de esos factores. Aquí, el pescador jubilado deja de ser pescador en el sentido de eje relacional del grupo (recordemos la identificación a través de la ejecución efectiva del oficio). De ahí que un pescador jubilado pueda tener un huerto, y pesque de recreo, así como que sea más fácil que un excampesino salga algún día con su pequeño llaüt, su pastera o su bot, a "coger un par de verderols o de serrans".

\subsection{La imagen especular}

En el espacio cotidiano de la propia identidad, los significantes, los referentes de uno y otro grupo son utilizados de manera que, desde una perspectiva exterior, parecen mutuamente intraducibles. Pero no se trata tanto de mundos diferentes, sino de las dos vertientes del espejo. La imagen aliciana no parece muy lejana de la realidad: si el "terrestre" construye su espacio relacional utilizando topónimos y corónimos con significados estructurados ad hoc en cada ámbito geográfico concreto (la finca, el pueblo, la comarca, la isla) el marinero hace lo mismo, pero desde el otro lado. Sus referencias, sus senyals costeras son inaccesibles para el campesino, aunque se trate de los mismos accidentes observados desde la mar: su visión del mundo isleño es justo la que aparece oculta para aquél. El pescador toma referencias incluso del Monte Toro, la única altura importante $(300 \mathrm{~m})$ situada en el centro de la isla, para ubicar las redes, para evitar que "la mar engañe... que engaña mucho".

Pero hay más. Para el campesino los elementos orográficos son comunes, grupales: en ello le va la relación; inclusive la derivación y repetición generacional y comunicacional. El pescador tiene sus señales, son

\footnotetext{
24 Ibidem.
} 
sólo suyas; generacionalmente también, pero exclusivas de cada unilinea de derivación. Esta segunda y tan distinta utilización del espacio referencial, además, redunda en el factor identificador pescador por antonomasia: las señales no están siempre ahí, sino que se reactivan, en correlación con corrientes, vientos, oleaje, en el momento mismo de pescar; es decir, cuando el pescador se construye socialmente, cuando, identitariamente, es. "Las montañas indican la pesquera... es sabiduría de viejo... yo lo he aprendido... es una cadena".

Lo que resulta fundamental es la común estructura de conformación del mapa referencial junto a la absoluta individualidad de cada concreta triangulación. Cada pescador tiene sus "propias ideas" sobre cómo pescar: aunque se calen las redes en el mismo lugar, cada uno tiene sus propias normas, sus propios puntos.

Con respecto al conocimiento de las especies también se produce una cierta inversión especular en relación al mundo campesino: para éste los vegetales y animales son comunes, aunque la específica adjetivación sea utilizada como factor de diferenciación (mis cerdos con respecto a los suyos; mis cultivos en comparación a tales otros; nuestro aceite es mejor por tal y tal otro componente de la tierra o sistema de trabajo aplicado); en el pescador cada especie sustenta la valoración moral positiva de cada subagrupación en función del discurso laboral: así la langosta buena se capturará sólo si las referencias espaciales construidas y/o heredadas son las correctas, conociendo a la perfección dónde está la pastura (lit. pasto) ideal para la alimentación del crustáceo, donde los fondos correctos, cuándo se pescó demasiado en tal zona y qué nuevos caladeros son aconsejables. En definitiva, si se conoce al animal concreto de la zona concreta, sus costumbres, incluso si se las sabe engañar es porque "ellas lo ven".

\subsection{El espacio y los tipos de pesca}

Como comenté antes, si exceptuamos las "dos capitales", Ciutadella y Maó, las bases portuarias pescadoras se reducen a Fornells, en el norte, y Cales Fonts, en el sureste; el resto de calas son utilizadas como referencias de pesqueres, como tales en sí mismas o como refugios temporales. Un ejemplo de estas últimas es Cales Coves, en el sureste: se trata de una cala cerrada, rodeada de cuevas (según los pescadores, de invierno y de verano), donde recalaban los pescadores norteños en los meses invernales. La ausencia de medios de transporte les obligaba a centrar sus faenas allá, así como a trasportar el pescado a la vecina Maó, a pie. Actualmente las cuevas están ocupadas por jóvenes hippies, como los deno- 
minan sus anteriores usuarios. Desde hace unos años, con la entrada del turismo, se han constituido poblamientos costeros no pescadores directamente, pero que permiten una cierta concentración de llaüts, normalmente de aficionados o semiprofesionales. La substitución de la vela por el motor y la ya mencionada mejora de vías y medios de comunicación hacen posible esta transformación de temporalidad de estancia en permanencia.

Ello no es óbice para que los pescadores tiendan a mantener las zonas de pesca "derivadas" de sus bases. La explicación emic de tal continuidad se centra en el conocimiento de las señales: si un pescador sale de su zona debe regirse por los barcos locales, con lo que, además de poder cometer el error de calar sobre otros artes, llega a producirse un juego ritualizado de amagos y engaños para evitar la competencia. Los bous de mayor tamaño, normalmente foráneos, sí actúan de esta manera, llevando a los pescadores locales a la indignación: se rigen por los movimientos de éstos, calan cerca de ellos y terminan por robarles la mitad del pescado. Independientemente de la diferencia de embarcaciones y sistemas de pesca, lo que subyace es la apropiación del espacio: aquellos vienen de fuera, roban nuestro pescado. Exactamente lo mismo que hallábamos en Mallorca al hablar de la Albufera.

Sin embargo, como sucede también en el mundo campesino y en el pescador del resto del archipiélago, estas transgresiones de las fronteras son narradas tan sólo como hipótesis para sí mismos, y como realidades cuando se busca el ejemplo en los otros: un pescador ibicenco (caso único) asentado en Menorca que se va del espacio de pertenencia e invade otros; uno de Ciutadella que entra en la zona de Fornells. Por lo tanto, del diacrítico genérico pescadores/no pescadores, se pasa al específico de los pescadores de aquí/ los de allá. La isla como referencia global, también funciona aquí de forma inversa a como lo hace con respecto al universo terrestre: las referencias Tramuntana/Mitjorn (norte/sur) no son relativas para los pescadores, sino absolutas.

Retomando la idea del trabajo/sacrificio (dureza, peligro, rentabilidad con honradez y esfuerzo), los norteños, aduciendo las peores condiciones climáticas, los fondos más rocosos, las costas más escarpadas, se sitúan por encima de los sureños, con bonanzas, arenas y calas más accesibles: "en el norte tienes que saber más puestos de pesca, tienes que saber más de pescar. Los meridionales aplican criterios diferentes para fortalecer su esencia: los septentrionales salen menos por la Tramuntana, trabajan menos, y tienen el puerto de Fornells como protección privilegiada. Si a ello añadimos que los Bous de mayor tonelaje pueden faenar mejor en el sur que en el norte, podemos cerrar el mapa relacional de las diferencias internas a la isla. $\mathrm{Si}$, finalmente, incorporamos el resto del archipiélago, 
podemos substantivar la afirmación inicial respecto a la inexistencia identificadora del concepto Baleares: no se conocen pescadores mallorquines, porque los menorquines siempre permanecen en sus espacios; sin embargo sí es posible que los de la Balear Mayor, inclusive los pitiusos (cosa harto difícil, habida cuenta de las características de la flota de allí y de las dificultades navegatorias entre ambos espacios) invadan sus aguas. Pero no por provenir de las islas hermanas se articulan de manera diferente a aquella en que lo hacen los alicantinos, tarraconenses o, inclusive italianos: "nos cogen nuestro pescado".

En definitiva, el pescador crea su propio espacio identificador con mayor fuerza que ningún otro grupo isleño. Se conserva con celo extremado: nadie debe conocer tu redol (espacio de pesquera conocido mediante señas propias); ningún pescador te dirá nunca cómo sitúa la pesquería, como "un buscador de setas jamás te contará donde las encuentra".

\section{LAS PITIUSAS: EL MAR COMPARTIDO}

Si el oficio de pescar es el factor definitivo en la construcción diferencial del pescador con respecto al campesino y al terrestre genérico en las dos Baleares, las Pitiusas nos presentan una situación abiertamente turbadora de aquél argumento: los pagesos pueden ser y de hecho son pescadores. La mayoría de las veces manejarán pequeños llaüts o bots de lista 4." o $5 .^{a}$, pero sin que la categorización oficial como "aficionados" impregne en absoluto ni sus relaciones ni sus actividades pesqueras. De hecho, como ellos mismos declaran, lo que da el nombre a la barca es la pesquería, la especie a la que se dedique y no la específica construcción y el tamaño.

\subsection{Pesca y agricultura: oficio e identidad}

La pobreza relativa y absoluta de las dos islas meridionales del archipiélago, el minifundismo rabioso y las formas de tenencia, han sido siempre un factor de expulsión de sus habitantes hacia el exterior; al menos hasta bien entrado el fenómeno turístico en los 60 y 70. Así, en Formentera, "tenían que lanzarse a la mar", no sólo como pescadores, sino también como marineros embarcados en mercantes. Pilotos, patrones de altura formenterenses, "los encontrarás en todo el mundo". En Eivissa, isla mayor y con más elementos agrícolas de subsistencia, "quien más, quien menos, si tiene una barca o le dejan, pesca". Ya a nivel declarativo, no 
se produce la ruptura que veíamos en los espacios anteriores: ambos universos se presentan conformando un agrupamiento anterior que no ha llegado a desgajarse; la generalización de las causas impide la excepcionalidad que allí encontrábamos.

No es que los campesinos "se hagan la vida en el mar", pero, una vez acabadas las labores, los hay que "incluso hacen una semana - de pescar- si el tiempo es bueno". En Formentera, donde la vida es dura, sin agua, miserable - "ólo el turismo les da un poco de vida"-, "no encontrarás un formenterense viejo que ya casi no saben andar, y saben inglés, y alemán: no encontrarás a nadie, en Baleares, que pueda con los patrones y marineros de Formenteran. La introducción del campesino en el espacio físico y relacional marino es función de los ciclos agrícolas y de la capacidad productiva de la tierra.

Por lo tanto seguimos manteniendo una causa prima equivalente a la del resto del archipiélago: la pesca aparece, tanto para los campesinopescadores como para los pescadores exclusivos, a partir de la agricultura; pero a diferencia de las dos Baleares en sentido estricto, en las Pitiusas no se produce una ruptura histórica y estructural, sino que la separación paulatina o radical del campo y la aparición de la pesca se dan al unísono; sólo el hecho de embarcar-se desgaja al protagonista de sus raíces terrarias.

Si la segmentación en dos grupos diferenciados tiene así menos posibilidades de producirse, al menos por lo que respecta a los pescadores de llaüt (hablamos de cuatro o cinco metros de eslora), implica al tiempo el engarce de la pesca en la agricultura siempre y en todo lugar. La "afición" (relativa en tanto supone una esencial aportación alimentaria cuando no monetaria al grupo de producción campesino) puede surgir espontáneamente, pero, por lo general, es resultado de líneas generacionalmente previas: los que no son pescadores, porque no les viene de berencia, son cazadores o trabajan en la montaña (carboneros, fabricantes de encrit -alquitrán vegetal-); los que sí lo son, no se limitan al volantí o a la fluixa (currican), sino que calan trasmallos y redes llagosteres. En el último caso, además, la pesca llega a primar sobre la agricultura misma: "Cuando había ido a calar la red, a lo mejor venía a casa a trabajar". La importancia de tal prioridad llega a afectar inclusive a la jerarquía y división de roles de la familia campesina misma: si en Mallorca y en Menorca la mujer no accede (identitariamente, otra cuestión es cada realidad concreta) a los papeles y tareas considerados centrales en el agro, en las Pitiusas la mujer, los hijos jóvenes, se hacen cargo de la finca mientras el amo se hace patró. Sa madona ocupa espacios de responsabilidad masculina en la finca, pero no puede hacer lo propio con respec- 
to a los pesqueros. No puedo substraerme a la tentación de transcribir una declaración de un campesino del norte de Eivissa que expresa mejor que cualquier análisis la relación que acabo de describir: "Antes dejará pudrirse las almendras, malograrse un campo de trigo, que dejar de pescar; claro que, hacerlo, lo podrá hacer la mujer que está en casa ${ }^{25}$ o él mismo los sábados y domingos, que no se puede pescar.. Si se sostiene la centralidad campesina de las identidades básicas (y debe hacerse así ante la etnografía y los análisis realizados ${ }^{26}$ ), la mujer queda como mantenedora mientras el hombre aparece como definidor. Los pescadores-campesinos se definen a sí mismos, de hecho, como "pagesos de propiedad y pescadores de profesión", que "entienden a la tierra como si no fuesen pescadores y a la pesca como si no fuesen pagesos" ${ }^{27}$.

Aquél concepto de trabajo/sacrificio/seguridad/riesgo que veíamos en las otras islas enfrentado al peligro/menor esfuerzo del pescador, queda aquí desposeído de aquella función demarcadora.

\subsection{Pesca y agricultura: elementos de la una en la otra}

Sin duda la caza está ligada intrínsecamente al universo agrícola; la pesca no parece situarse en el mismo ámbito de referentes. Los informantes suelen resolver la dicotomía hablando de afición; pero, como hemos visto, ésta no tiene nada que ver con la propia de ciutadans, senyors o extranjeros. Actualmente la posible tensión entre profesión y entretenimiento no se produce ante la apabullante presencia de la determinación turística, pero subsiste en la definición que los pitiusos hacen de sí mismos.

Hoy en día la pesca del campesino, normalmente de forma directa o derivada (algún miembro de su familia) imbricado en el universo del Sector Servicios (hostelería fundamentalmente), ha variado su función económica: ahora sí que lo hace por afición, para coger pescado para comer en casa. La venta es cosa de los profesionales que se dedican. Puede que alguno venda al vecino no pescador algo de pescado, pero la pesca ya no

25 Ésta puede ser la madre, la esposa, una hermana soltera, incluso una hija o una ahijada.

26 Tesis doctoral. A. MiQuel, op. cit., pp. 1076 y ss.

27 El concepto "propiedad" en Eivissa es relativo, ya que a menudo se confunde propiedad de la tierra con propiedad de la casa. Al no existir históricamente poblaciones nucleadas, sino casas con referencia parroquial, la cuestión debe relativizarse. Ver tesis, A. Miquel Novajra, op. cit., y J. Bestard, Casa y familia. Parentesco y reproducción doméstica en Formentera (Palma de Mallorca: Institut d'Estudis Baleàrics, 1986). 
supone un factor de supervivencia fundamental, substituida por el nuevo marco de relaciones y mercado.

Por lo tanto debemos buscar el posible elemento diferenciador en el factor complementariedad/exclusividad. Una primera gradación es geográfica: los del norte (Sant Joan de Llabritja), "son más pescadores, quien más quien menos, tiene su llaütet y sale a pescar cuando el trabajo se lo permiten. Una segunda es de posición observacional; de hecho, el tratar de hallar aquí la especularidad incompartible aparecida en las dos Baleares, resultaría infructuoso: la relación espacial misma, con soporte orográfico, es esencialmente común, compartida. Las señas invertidas, imposibles de construir desde la tierra, no pueden surgir de un mundo exclusivamente campesino. Más aún cuando no sólo se trata de referencias espaciales, sino de trasmisiones consuetudinarias exclusivamente marineras: si hay luna durante la noche, el pez come, y si ha comido toda la noche, no lo hará de día; según el viento que sople, el xaloc (siroco), "se pesca o se pesca menos; si el pez ha comido con un viento, al cambiar, a lo mejor ya va mejor y pica".

Se toman tres puntos de referencia en la costa para situar correctamente la pesquera; y sólo los conoce quien es propio de ese lugar. el que encuentra el redol bo (la pesquería buena), se lo guarda para sí y no se lo dice a nadie. Exactamente lo mismo que hallábamos en Menorca, con la diferencia esencial de que aquí no hablamos de pescadores con pescadores, sino de campesinos en la mar; unos marineros de tierra que, además, se distinguen claramente de los aficionados por su pericia y conocimiento. El término "recreo", establecido a nivel burocrático, se mantiene aquí, pero su contenido semántico difiere mucho del de las otras islas: no se trata ya de barcas que no son prácticas, ni de los que vienen y no saben calar, sino de auténticos hombres de mar.

Pero ¿qué hace que un campesino se inicie en la pesca? Alguien tiene que aprender el uso de los artes, las señas, hasta el punto de dominar plenamente el espacio marino donde se desenvuelve, para luego trasmitirlo. En los casos de ascendientes campesino-pescadores, la herencia de la barca va, por lo común, insoslayablemente unida a la de la casa y la tierra: el sistema de espolits — capitulaciones matrimoniales con el nombramiento de heredero conjunto (hay separación de bienes en el fuero balear) primogénito $\mathrm{o}$ "mejor visto" - sigue prevaleciendo en la práctica por encima del código civil. Parece que se constituye una unilinealidad mayoritaria en ese sentido. Sin embargo el incremento relativo de capacidad adquisitiva nacido con el turismo (alquileres de casas costeras antes improductivas; trabajo en temporada en la hostelería), reduce por una parte el factor <necesidad $>$ de la pesca $y$, por otro, incrementa la posibilidad de adquisición 
de nuevas embarcaciones en los no herederos. Aunque lo fundamental, el aprendizaje, sigue ligado a la derivación agnaticia.

Durante toda esta digresión hemos planeado por encima de la profesionalidad pescadora exclusiva sin aterrizar plenamente en ella: ¿cabe hablar de un grupo pescador, además del campesino que pesca, constituido de manera similar a los hallados en el resto del archipiélago? El factor "temporada" está en la base de la respuesta.

\subsection{El pescador "sólo pescador"}

El concepto "tiempo de distancia del mar", actualmente intrascendente, ha sido, hasta bien entrada la segunda mitad del presente siglo, determinante en este sentido. Los habitantes del interior de Santa Gertrudis o de Sant Llorenç (pueblos, pero no municipios. Los ibicencos siguen midiendo por el primero y no por el segundo de los criterios), son los menos pescadores, si acaso de recreo o incluso de caña. Por lo tanto la cercanía al litoral parece ser definitoria y definitiva. El segundo factor es el tamaño y tipo de barca; más bien, éstos dependen de la dedicación efectiva del patrón que los gobierne. Los llaüts y bots ibicencos son las únicas embarcaciones de los campesinos-pescadores: es decir, no superiores a los seis o siete metros máximos de eslora y por ende literalmente pegados a la costa, a la costa de cada espacio terrestre de partida. En el caso de que éste linde con la finca de propiedad o de explotación, la referencia y la religación coincidirán, incrementando de esta manera el mantenimiento identitario territorial.

En consecuencia, si el referente principal no es la costa, sino el mar, volvemos a los planteamientos de las dos Baleares: lo de fuera, aquello que no es nuestro. Los que se mueven en este ámbito físico y de definición son precisamente aquellos que viven exclusivamente de la pesca, los que no ban tenido nunca propiedad de tierras; son o se ban becho de Vila (Eivissa capital), Sant Antoni y Santa Eulària, los puertos propiamente dichos. Tienen barcas buenas y no tienen tierra ni nada. Hacen pesca de altura, de bou, van a mucha profundidad.

La carencia de propiedad, como en las otras islas, es lo que hace del pescador un pescador exclusivo; el hecho de que se dedique al arrastre, a la pesca de altura y pase más tiempo en la mar, tan sólo aparece aquí como lógico efecto de la causa primera.

Queda, no obstante, un pequeño pero importante hueco en el razonamiento: en qué radica exactamente esa profesionalidad exclusiva desde la perspectiva del protagonista. El tamaño de la barca, a pesar de lo que 
comentaba líneas arriba, no es esencial, ya que los pescadores profesionales «empezamos con un llaüt de diecisiete palmos, pasamos a uno de veinte que hicimos nosotros, y ahora tenemos uno de veintisiete; también hemos comprado una barquita de diez metros y medio y ahora he preparado ésta de arrastre hace unos siete años". Lo importante es que uno viva de su profesión, de la pesca. Hay muchos que son profesionales, pero sólo de temporada, que empiezan a calar las redes llagosteres en abril y, cuando llega la veda, vuelven a la tierra, y el llaüt dentro de la casa. Son la gente que vive del campo, los llaüts de la costa. Aunque también los hay de costa que pescan todo el año: en invierno, con palangres, calamares y lo que se puede pescar en invierno; en verano, con red llagostera (una especie de trasmallo de dos mallas) y trasmall.

Tomándome una licencia biologista-filosófica, podría decir que tenemos dos argumentaciones. La primera, ontológica, nos muestra el paso a pescador profesional: el que vive de la pesca. La segunda, filológica, sitúa la diferencia entre pescadores de altura y de costa; los últimos comparten de tal manera el espacio con los campesino-pescadores, que parecen pertenecer más a éstos que a los anteriores. De ahí que, en lugar de insistir en el trabajo/sacrificio, en el peligro, en la inseguridad, como veíamos en las otras islas, se articule aquí la profesionalidad diferencial en torno a la estima; o, en otros términos más inmediatos, a la opción. El pescador está más apegado a su trabajo; los campesinos, aún los campesinos-pescadores, han preferido irse a trabajar a la más rentable y segura (en otro contexto) hostelería.

Sin embargo el pescador, sin dejar de ser marinero, también puede acercarse a esa miel más clara y densa: las excursiones de turistas. A pesar de que he podido constatar este hecho, los profesionales lo niegan taxativamente, situándolo tan sólo en la excepción individual: los campesino-pescadores que son realmente pescadores de alma, terminan por hacerse pescadores profesionales; los que prefieren la tierra pero controlan la navegación, se pasan a las golondrinas (barcos de paseo), porque es un trabajo más seguro; pero un auténtico pescador tiene más cuidado de lo suyo, no se preocupa de esas cosas. Para certificar ese apego, la declaración de que "nadie tiene nada de tierra, todos somos pescadores de siempren, viene a certificar, a nivel de identidad, lo que a nivel efectivo es más que dudoso.

Las declaraciones de exclusividad, en este mundo pitiuso donde se imbrican mar y campo de manera inextricable, los matrimonios mixtos sólo son planteados como tales ante la pregunta concreta; no acontece, como sí ocurre en las dos Baleares, que las pertenencias diferenciales de los cónyuges choquen o exijan opción. Dice un viejo patrón de Sant Antoni (en el oeste de la isla) que "yo estoy casado con una pagesa, y de toda 
su familia no hay nadie que se haya mojado los pies en agua salada nunca. Nunca se ha mirado eso, siempre ha habido una gran armonía entre pagesos y pescadores". Sin embargo surge una pregunta inmediata: ¿qué hace con respecto a la tierra un marinero profesional que, por matrimonio, tiene acceso a ella? La respuesta es taxativa: o la dejará para hacer borrajas o la dejará a unos andaluces (y el foraster vuelve a aparecer como totalmente excluido del organigrama identitario); un marinero nunca dejará la pesca para ir al campo. Naturalmente el hecho foral de la separación de bienes viene a fortalecer esa negativa esencial.

La no admisión de la continuidad, cuanto menos la contigüidad, entre el trabajo y la pertenencia campesinos y los pescadores resulta como efecto añadido: siempre han sido pescadores, o, como máximo, han estado embarcados, nunca han dependido de otra cosa que no sea la mar: nunca he sido pagès, es la declaración más habitual, no sólo a nivel individual, sino incluso de derivación. La historia de cada familia, no obstante, nos muestra que, más que el no haber sido, hay que leer el no haber podido ser: en ello les va la identidad. Los herederos excluidos o mal dotados por su jerarquía de nacimiento, no aparecen aquí, por ende, no ya como marineros por necesidad, sino tan siquiera como iniciadores de líneas de herencia marinera. Una vez más, la generación se reconstruye desde el presente.

La explicación se substituye con la experiencia: "cuanto más estás en la mar, cuantos más temporales cojas, más sabes, más profesional eres; aquél que sólo va cuatro días, no puede saber lo que sabe el que va siete por semanan.

Si la isla aparece como una globalidad relativamente indivisa, si la profesionalidad pescadora no puede basarse en referentes costeros porque éstos se comparten con los campesinos-pescadores, resulta obvio que la indiferenciación de proveniencia debe ser superior en las Pitiusas. En principio es así, y la pertenencia espacial no se tiene presente para ser companyero (sic) de pesca. Incluso los forasters entran sin fricciones en la categoría (no sin señalarse antes que lo son): la marinería se compenetra, bay armonia, tanto si son del sur (Andalucía), como de Ses Illes, como del norte (costa norte mediterránea), se compenetran en seguida. He dicho "en principio", porque existe una base estructuradora de las genealogías pitiusas que abarca ambos grupos: ses cases; es decir, la casa (en sentido agnaticio fundamentalmente y, además, stricto sensu) de las religaciones primordiales ${ }^{28}$. Por lo tanto la presencia de forasters en cual-

28 A. MiQuel, "Antropología e identidad: una reflexión balear desde los presupuestos hermenéuticos de Lisón", Antropología sin fronteras. Ensayos en bonor de Carmelo Lisón (Madrid: CIS, 1992), pp. 543-559. 
quiera de los dos mundos, sea el campesino (estructuralmente casi imposible) como el marinero, crea cierta conflictividad estructural.

7. EL MAR PERDIÉNDOSE EN LA CONSCIENCIA; EL MAR COMO ATRACTIVO TURÍSTICO

La reducción del número de pescadores surge de dos factores coadyuvantes. El primero, interno, de las dificultades para renovar la flota y superar la competencia con las artes y técnicas de los grandes bous foráneos. El segundo, externo, el mayor atractivo y seguridad de la economía turística directamente asumida.

Hasta la entrada del boom a partir de los sesenta, el pescador era miserable, estaba empujado a hacerse a la mar por la imposibilidad de ligarse a la tierra; pero, al tiempo, cientos de campesinos pobres evitaban esta salida prefiriendo los duros y poco rentables trabajos de montaña. Por consiguiente hay una identidad específicamente pescadora al margen del factor necesidad que, además, se patentiza por la continuidad generacional, por la herencia de barcas, artes, oficio, señas, valores, pertenencias. Al asumir el rol secundario y a menudo marginado en la construcción de las identidades isleñas, los pescadores manejaban estrategias de defensa identaria que aún permanecen en su universo simbólico, ya que "la asunción de la posición subordinada por parte de un grupo, tiene como límite su propia autonegación" ${ }^{29}$. Así, mediante su actuación al margen en algunos campos de la cultura dominante (Partial escape), sitúan su pertenencia espacial: fiestas propias, mitos fundantes, terminología marinera, fiscifagia predominante, dominio del arte de marear. A través de la evitación de ciertos contactos con los miembros de los otros grupos (Advoidance), mantienen la derivación generacional: reducción de matrimonios mixtos, mantenimiento de los referentes (Eivissa) cuando éstos se producen, continuidad espacial en sus barrios originarios. Mediante el uso de códigos endógenos (Covert agression) desconocidos por otros grupos, defienden el lenguaje de comunicación interna: el ya mencionado lenguaje pescador, el "acento" de cada espacio marinero, el uso específico del mallorquín frente a forasters y extranjeros.

Con todo ello, el mar se pierde, cambia de manos, de uso y de significación. Frente a los marineros de vela latina que llegaron hasta bien

29 J. DAvis, People of the Mediterranean. An essay on comparative social anthropology (London: Routledge \& Kegan Paul, 1977); A. MelucCI y M. DiANI, Nazioni senza stato (Torino: Loescher, 1983). 
entrados los setenta, los enormes yates, los veleros de competición, las motoras, las golondrinas atestan las playas y los puertos deportivos isleños. Mientras el pescador se entierra cada vez más al lado de aquí de las costas, los aficionados de Ciutat, algunos campesinos enriquecidos por el turismo y miles de extranjeros, navegan por las costas sin reconocer aquella orografía pesquera que tantos y tantos años tardó en constituirse; a menudo son los propios pescadores viejos, ya insertados en otros mundos, los que acompañan, también de recreo a los nuevos amos de las aguas.

Este artículo aborda a tres niveles las relaciones entre las construcciones de las culturas de las Islas Baleares y el mar como espacio social, económico e identificador. El primer nivel analiza el papel secundario que, paradójicamente, desempeñan los elementos culturales marítimos en las identidades isleñas. El segundo aborda los mecanismos diferentes mediante los cuales se conciben los mundos marineros desde las identidades terrestres y mayoritarias de cada una de las islas componentes. Finalmente, explica los componentes fundamentales de las percepciones, relaciones y reproducciones culturales de los pescadores de cada uno de los espacios analizados. Todo ello en el marco de un universo socioeconómico centrado en el turismo de masas.

The author approaches from three angles the connections between the culture of the Balearic Islands and the sea as social, economic and identifying space, within the larger socio-economic context of mass tourism on the Islands. First, he analyzes the paradoxically secondary role that maritime cultural elements play in the identity of the Islanders. Then, he discusses the different mechanism by which life at sea is perceived from the standpoint of the earthbound identities prevalent in the archipelago. Finally, he explains the key components of the perceptions, relationships and cultural reproductions of fishermen in each of the spaces considered. 